\title{
Bias due to incomplete follow up in a cohort study
}

\author{
P M Pennefather, W Tin, M P Clarke, J Dutton, S Fritz, E N Hey
}

\begin{abstract}
Aim-To investigate the bias introduced by incomplete follow up in a cohort study of ocular outcome after premature birth. Methods-A geographically defined cohort of children born before 32 weeks' gestation was prospectively recruited at birth to study the ocular outcome at 2 years. On the basis of attendance at 2 years, the children's families were allocated to one of three groups: group 1 attended for follow up, group 2 were difficult to trace, and group 3 were very reluctant for assessment. All children were examined by a single ophthalmologist, masked to these groupings.
\end{abstract}

Results-558 children $(98.8 \%$ of study group) were examined, of whom 505 were in group 1, 20 in group 2, and 33 in group 3 . The groups which were more difficult to study (groups 2 and 3 ) showed a significantly higher prevalence of ocular abnormalities, including strabismus $(p=0.02)$ and cicatricial retinopathy of prematurity $(p=0.002)$ compared with those attending for follow up. Further, not all of these cases could have been identified by review of the children's previous records. Ocular abnormalities would be underestimated by $16 \%(11.3 \%$ in group 1 compared with $13.4 \%$ in the total cohort, $p=0.77$ ).

Conclusions-This study suggests that the prevalence of abnormalities would be underestimated by incomplete follow up, as those subjects who were most difficult to obtain for study had a significantly higher prevalence of abnormalities.

(Br F Ophthalmol 1999;83:643-645)

Survey Office,

Newcastle upon Tyne

W Tin

$S$ Fritz

E N Hey

Department of Clinical Audit, Southport and

Formby District

General Hospital, Southport

J Dutton

Correspondence to:

P M Pennefather, Royal

Liverpool Children's

Hospital, Eaton Road,

Liverpool L12 2AP.

Accepted for publication 8 February 1999 efforts were made to achieve complete follow up for a geographically defined cohort of children born before 32 weeks' gestation. This allowed us to investigate the rates of ocular abnormalities at 2 years of age in those unlikely to have attended follow up under routine conditions $(9.5 \%)$ compared with those attending as a routine $(90.5 \%)$.

\section{Methods}

The study group consisted of all children born before 32 weeks' gestation between 1 January 1990 and 31 December 1991 to mothers resident in the Northern Region of the National Health Service, who survived until 2 years old $(n=565)$. This region has a population of approximately three million. Ethics committees approved this prospective study and informed parental consent was obtained at the child's birth.

All children were reviewed at 24 months of age by a single, experienced paediatrician. This review included medical, neurological, and developmental assessment. Children were reviewed at a hospital or community clinic or home visit. On the basis of attendance for paediatric review at 2 years, the children's families were allocated to one of three groups: group 1 attended for follow up within three appointments ("routine attainment"), group 2 were difficult to trace, and group 3 were very reluctant for assessment. Families were classified as difficult to trace (group 2) if, after discharge from hospital, they had moved at least twice, moved out of the region, or changed both the forename and surname of the child. Families were classified as reluctant for assessment (group 3) if they repeatedly failed to keep previously agreed appointments without any explanation (3-6 appointments). Children who had been adopted or fostered were also grouped with those reluctant for assessment because the Department of Social Services is very reluctant to grant access to these children for study purposes.

On a subsequent appointment, all children were reviewed by one ophthalmologist when aged between 2 and 3 years old. The examiner was masked to gestation age, neonatal events, all hospital notes, and attendance grouping.

Examination included visual acuity (usually by Kay pictures) and orthoptic assessment. Topical cyclopentolate $1 \%$ was instilled 20 minutes before refraction and funduscopy. The main outcome measures were strabismus and cicatricial retinopathy of prematurity (despite cryotherapy for those neonates found to have threshold stage III "plus" acute retinopathy of 
Table 1 Prevalence of strabismus, cicatricial retinopathy of prematurity, and cerebral palsy in children born before 32 weeks'gestation according to whether the family attended for follow up at 2 years as a routine (group 1), were difficult to trace (group 2), or were very reluctant to attend (group 3). Significance levels are for comparisons with group 1

\begin{tabular}{|c|c|c|c|c|}
\hline & $\begin{array}{l}\text { Group } 1 \\
(n=505)\end{array}$ & $\begin{array}{l}\text { Group } 2 \\
(n=20)\end{array}$ & $\begin{array}{l}\text { Group } 3 \\
(n=33)\end{array}$ & $\begin{array}{l}\text { Total } \\
(n=558)\end{array}$ \\
\hline \multicolumn{5}{|l|}{ Strabismus: } \\
\hline Incidence & \multirow[t]{3}{*}{$53(10.5 \%)$} & $4(20.0 \%)$ & $13(39.4 \%)$ & \multirow[t]{3}{*}{$70(12.5 \%)$} \\
\hline $\mathrm{RR}(95 \% \mathrm{CI})$ & & $2.13(0.69,6.61)$ & $5.54(2.61,11.78)$ & \\
\hline $\mathrm{p}$ value & & 0.19 & $<0.001$ & \\
\hline \multicolumn{5}{|l|}{ Cicatricial ROP: } \\
\hline Incidence & \multirow[t]{3}{*}{$10(2.0 \%)$} & 0 & $6(18.2 \%)$ & \multirow[t]{3}{*}{$16(2.9 \%)$} \\
\hline $\mathrm{RR}(95 \% \mathrm{CI})$ & & $0.005(0, \&)$ & $10.91(3.69,32.25)$ & \\
\hline $\mathrm{p}$ value & & 0.81 & $<0.001$ & \\
\hline \multicolumn{5}{|l|}{ Cerebral palsy: } \\
\hline Incidence & \multirow[t]{3}{*}{$37(7.3 \%)$} & $2(10.0 \%)$ & $15(45.5 \%)$ & \multirow[t]{3}{*}{$54(9.7 \%)$} \\
\hline $\mathrm{RR}(95 \% \mathrm{CI})$ & & $1.41(0.31,6.29)$ & $10.54(4.92,22.60)$ & \\
\hline $\mathrm{p}$ value & & 0.66 & $<0.001$ & \\
\hline
\end{tabular}

prematurity $^{7}$ ). Cicatricial retinopathy of prematurity (ROP) was defined as tractional changes of the posterior pole vessels or at the periphery or worse. Once the child had been examined, all available notes were reviewed for any additional information such as the outcome of ocular examination under anaesthetic or cranial ultrasound scans. This information was used to augment that obtained from clinical examination.

Statistical analysis was performed using $\chi^{2}$ tests and multiple logistic regression (values for relative risk and confidence intervals were calculated from the coefficients from this regression).

\section{Results}

The parents of all eligible children gave consent for the study soon after the child's birth. Of the 565 surviving children, 558 (98.8\% of the study group) were examined at 2 years of age, of whom $505(90.5 \%)$ were in group 1, $20(3.6 \%)$ in group 2, and $33(5.9 \%)$ in group 3. Cicatricial ROP developed in 16 children (2.9\%), ranging from straightening of arcade vessels to open funnel detachments. Nine of these children had been treated with cryotherapy for threshold stage III acute ROP, two had reached subthreshold stage III acute ROP, and in five children screening had not been sufficient to indicate the worst stage of acute ROP.

The prevalence of cicatricial ROP was significantly higher in the children of families who were reluctant to attend for assessment (group 3, 18.2\%) compared with those attending as a routine (group 1, 2\%, p<0.001, Table 1). Similarly, there was a higher prevalence of strabismus (group 3: $39.4 \%$ compared with group 1: $10.5 \%, \mathrm{p}<0.001$, Table 1) and cerebral palsy (group 3: $45.5 \%$ compared with group 1: $7.3 \%, \mathrm{p}<0.001$, Table 1). Group 2 had a slightly higher prevalence of strabismus and cerebral palsy than group 1 but this difference was not statistically significant (Table 1 ).

The prevalence of abnormalities in those attending as a routine (group 1,90.5\% of the total population) underestimated the prevalence of abnormalities in the total study group. This difference was not statistically significant. Thus, in group $1,14.9 \%$ had one or more abnormality (strabismus, cicatricial ROP, or cerebral palsy) compared with $17.6 \%$ in the total study population $(\mathrm{p}=0.70)$. Similarly, ocular abnormalities (strabismus or cicatricial ROP or both) were present in $11.3 \%$ of group 1 compared with $13.4 \%$ in the total study population $(\mathrm{p}=0.77)$.

The incidence of previously unidentified ocular abnormalities revealed by the study examination was similar in the three groups $(17.4 \%, 15.0 \%$, and $21.9 \%$ in groups 1,2 , and 3 respectively, $\mathrm{p}=0.80$ ).

\section{Discussion}

One might expect that families of children with problems after preterm birth would be more likely to attend a comprehensive screening assessment offered at 2 years of age than those without problems. However, this study has shown that families of those with abnormalities are less likely to attend. This non-attendance did not solely reflect the fact that the children's problems had already been diagnosed, as some of the non-attenders had significant problems that were undiagnosed before the study examination. For example, three children had cicatricial ROP which was previously undiagnosed. In part, this reflected the families' reluctance to attend routine hospital referrals as well as the study review.

Reluctance for assessment may have been due to a variety of factors. In some families there was a clear resentment of all social ("authoritarian") intrusion. Some families showed frank hostility towards the medical profession, which in some cases was related to the child's disability or the way that the disability had first been revealed to the parents or subsequently handled. Some families seemed very stressed by caring for a very disabled child and were reluctant to tolerate another visit when they did not feel the child would benefit.

In this study the attainment rate was high even when excluding those who were difficult to trace or reluctant to attend. Families classified as attending as a routine constituted $90.5 \%$ of the study group, compared with total attainment rates of $33-87 \%$ at 18 months or more in many previous studies of outcome after preterm birth. ${ }^{1-7}$ Various factors may have contributed. This was a prospective study and consent was given to follow up soon after birth. Recruitment to the study was nurse coordinated and these lead nurses had the opportunity to form a relationship with the family before discharge from the neonatal unit. This recruitment included relatives such as grandparents who agreed to act as contacts for the study. The study was supported by all the consultant neonatologists in the region and the guidance and support of the child's general practitioner and health visitor were sought before approaching the family. Contact was made by telephone if possible rather than by letter, but in some cases, visits to relatives or a home visit were necessary to establish contact. Families were reviewed in their local hospital and a home visit was arranged if required by the family.

Families that were reluctant for assessment generally agreed after personal contact had been made at a home visit with a sympathetic discussion of their reasons for refusal. Families 
that demonstrated their reluctance for the assessment by being repeatedly absent from home at the times when they had previously agreed to a home visit from the paediatrician, were finally contacted when the paediatrician arrived for a home visit an hour before the agreed time.

The Department of Social Services was very reluctant to grant access to fostered and adopted children. Access was obtained only after prolonged negotiation with parents and their families, the Department of Social Services, and foster or adoptive parents, assisted by the parental consent given at birth. There were five children who were fostered or adopted by the age of 2 years (of whom two had cerebral palsy and one other had strabismus).

The higher prevalence of ocular abnormalities in children whose families were reluctant for assessment is supported by studies of developmental outcome after premature birth, ${ }^{10} 1113$ which show a lower general developmental quotient in children whose families were reluctant for assessment ${ }^{10}{ }^{11}$ or who failed to attend by 20 months of age. ${ }^{13}$ However, Campbell et al ${ }^{12}$ and Catlett et al ${ }^{14}$ found that failure to attend was more likely for the families of less premature children. These studies had a lower attainment rate $(74 \%$ and $72 \%$ respectively) than the present study and those of Wariyar et $a l^{10}$ and Tin et al ${ }^{11}$ (99-100\%) which may reflect additional biases in recruitment. For example, Campbell et al suggested the higher rate of non-attendance in the less premature may reflect a bias in recruitment owing to the varying efforts of caregivers to communicate to the families the importance of follow up.

In summary, this study has shown that the children of families who are reluctant for assessment have a significantly higher incidence of ocular abnormalities than those who attend as a routine. Recognition of this problem may assist in future cohort studies of children and in their interpretation if attain- ment is incomplete. This may be particularly important in comparisons of outcome if there are differences in the attainment rate in the groups. In this study the number who attended as a routine was high $(90.5 \%)$ and the $16 \%$ underestimate of ocular abnormalities that would be predicted for the whole cohort from these patients $(11.3 \%$ in routine attenders compared with $13.4 \%$ in the whole cohort) was not significant.

1 Grogaard JB, Lindstrom DP, Parker RA, et al. Increased survival rate in very low birth weight infants (1500 grams handicaps. F Pediatr 1990;117:139-46.

2 Page JM, Schneeweiss S, Whyte HEA, et al. Ocular sequelae in premature infants. Pediatrics 1993;92:787-90.

3 Dowdeswell HJ, Slater AM, Broomhall J, et al. Visual deficits in children born at less than 32 weeks' gestation with and without major ocular pathology and cerebral damage. $\mathrm{Br} F$ Ophthalmol 1995;79:447-52.

4 Burgess P, Johnson A. Ocular defects in infants of extremely low birth weight and low gestational age. Br f Ophthalmol 1991;75:84-7.

5 Weisglas-Kuperus N, Baerts W, Fetter WPF, et al. Neonatal cerebral ultrasound, neonatal neurology and perinatal conditions as predictors of neurodevelopmental outcome in very low birthweight infants. Early Hum Dev 1992;31:13148 .

6 Keith CG, Kitchen WH. Ocular morbidity in infants of very low birth weight. Br $\mathcal{F}$ Ophthalmol 1983;67:302-5.

7 Cryotherapy for Retinopathy of Prematurity Cooperative Group. The natural ocular outcome of premature birth and retinopathy. Status at 1 year. Arch Ophthalmol 1994;112: 903-12.

8 The Victorian Infant Collaborative Study Group. Neurosensory outcome at 5 years and extremely low birth weight. Arch Dis Child 1995;73:F143-6.

9 Robertson CMT, Hrynchyshyn GJ, Etches PC, et al. Population-based study of the incidence, complexity, and severity of neurologic disability among survivors weighing 500 through 1250 grams at birth: a comparison of two 500 through 1250 grams at birth: a com
birth cohorts. Pediatrics 1992;90:750-5.

10 Wariyar UK, Richmond S. Morbidity and preterm delivery-importance of $100 \%$ follow-up. Lancet 1989;i: delivery

11 Tin W, Fritz S, Wariyar U, et al. Outcome of very preterm birth: children reviewed with ease at 2 years differ from those followed up with difficulty. Arch Dis Child 1998;79: F83-7.

12 Campbell MK, Halinda E, Carlyle MJ, et al. Factors predictive of follow-up clinic attendance and developmental outcome in a regional cohort of very low birth weight infants. Am f Epidemiol 1993;138:704-13.

13 Wolke D, Shone B, Ohrt B, et al. Follow-up of preterm children: important to document dropouts. Lancet 1995; 345:447.

14 Catlett AT, Thompson RJ, Johndrow DA, et al. Risk status for dropping out of developmental followup for very low birth weight infants. Public Health Reports 1993;108:58994. 